\title{
Emphasizing Minimally Invasive Strategies for Improved Dental Care of Children
}

\author{
Robert L. Karlinsey* \\ *Indiana Nanotech, LLC, 7750 Centerstone Drive, Indianapolis, Indiana
}

Received: February, 18, 2017; Accepted: February, 24, 2017; Published: March 06, 2017

*Corresponding author: Robert L. Karlinsey, PhD, Indiana Nanotech, LLC,7750 Centerstone Drive, Indianapolis, Indiana 46259, Tel:317-3851578,Email:rlk.nanotech@gmail.com

\begin{abstract}
In the spirit of National Children's Dental Health Month, this paper highlights a few strategies that can be used to promote effective management of dental care for children, including fluoride modalities, effective dentist-patient communication, and minimally invasive recommendations for handling enamel lesions; in short, these strategies may serve to provide the child with a more patientcentered approach to improved oral care. At the same time, such management may potentially save the child's tooth structure from potentially counter-productive solutions involving 'drill and fill'.
\end{abstract}

Key words: Minimal intervention; Dentist-Patient Communication; Fluoride; Sealants; Non-cavitated lesions; Remineralization; Restorations; Children

Recently, the International Caries Consensus Collaboration (ICCC) convened, discussed and published their recommendations on the management of carious lesions [1]. One point of emphasis was the handling of non-cavitated lesions, where the council agreed the lesions were to be addressed through one or more of the following approaches: biofilm removal, remineralization, and/or sealing. When beyond repair, however, it follows that more invasive procedures are recommended [1,2]. It has been reported that four out of five children in the United States require dental restorations by the age of 17 [3]. This statistic speaks to the problems affecting youth, and echoes Dr. Miller's observation that "there is no doubt that a deterioration of the teeth accompanies the progress of civilization" [4].

In the spirit of National Children's Dental Health Month, this paper highlights a few strategies that can be used to promote effective management of dental care for children, including fluoride modalities, effective dentist-patient communication, and minimally invasive procedures for handling non-cavitated lesions; in short, these strategies may serve to provide the child with a more patient-centered approach to improved oral care. At the same time, such management may potentially save the child's tooth structure from invasive (and costly) solutions involving 'drill and fill'. Naturally, frank decay and health-challenging cases should opt for invasive procedures when minimal recourses will likely be insufficient. Nevertheless, it is beneficial to call to attention some existing and some evolving strategies that may help extend the life of the tooth structure and empower the child (and/or the child's parent/guardian) towards better oral health.

While the typical recommendations still stand (e.g. brushing at least twice a day or reduction of sugary enjoyments), it is helpful to be reminded of recommendations and guidelines put forth by various oral health agencies. In particular, the American Academy of Pediatric Dentistry (AAPD) published guidelines with respect to 'anticipatory guidance and preventive counseling, for infants, children, and adolescents' [5]. The AAPD strives to limit the development of early childhood caries, beginning within the first 12 months of the child's life [5]. In addition to patient education and counseling and the establishment of the 'dental home', application of fluoride varnish to limit or prevent tooth decay is an example of providing minimally invasive care [6]. Endorsed by national and international organizations, fluoride varnishes are essential in the fight against tooth decay and are recommended for children less than six years of age, with a variety of state-based programs providing access to dental care for those most in need and/or most economically disadvantaged, including fluoride varnish programs that can be applied by a registered and/or licensed clinician, including dentists, hygienists, physicians or nurses [7-13].

In addition to fluoride varnish, there are other effective fluoride modalities that are also minimally invasive. In participating communities, water fluoridation is an economical tool that provides tremendous public oral health benefits $[8,9,14]$. And, with water fluoridation now less than $1 \mathrm{ppm}$ in the United States water supply, the risk of developing fluorosis, which was already minimal at $1 \mathrm{ppm}$ fluoride, is even further reduced [15]. While standard over-the-counter fluoride toothpaste and rinses confer further protection for those at low or moderate risk for tooth decay, prescription-strength modalities (including toothpastes, gels, rinse, etc) can provide further protection and are recommended for higher risk patients [16-19]. Examples of children manifesting elevated risks for tooth decay include those wearing orthodontia or corrective appliances, those with special medical or dietary considerations, or even those demonstrating a history of invasive intervention.

Evaluation of a patient's habits, physical condition, general well-being and age-related behavior is foundational to minimal 
intervention success. As the child progresses through the various stages of tooth eruption, behaviors and choices can bear significantly on dental health. The key here is to ensure there is open communication and understanding between dental provider and family (i.e. the parents/guardians and the child) that includes expectations, goals and plans to address oral maladies and achieve optimum oral health. Though this may seem obvious and simple, this is not just wordplay: for example, Misra et al found that dentists recalled providing much more information and agreement on actions than patients remembered [20]. In fact, this disparity was found to be significantly different $(p<0.05)$ for the 26 consultations, with the dentists recalling almost twice as much dental advice than what the patients recalled. Though this was a small study, this study represents gaps in understanding that can be extrapolated to the 'real world' situation. Therefore, if patients (including parents/guardians of the children) may not fully understand the recommendations and instructions of the expert, might this not contribute to situations of poor patient compliance where the child and/or the parents do not recall (and therefore cannot perform) the recommendations? This is a point that should be stressed, especially since patients, like many of us, are likely inundated with myriad other details that life naturally presents. Strategies to improve compliance may include written instructions and/or periodic phone or e-mail follow-ups given shortly after and before the subsequent dental visit. Indeed, these approaches are part of a patient-centered approach where communication and oversight can help improve overall patient outcome [1,2,20-22].

A minimal intervention approach relies on retaining as much tooth structure as possible, while providing effective treatment that allows for a stable, healthy state [1,2,21,22]. A very common example of this occurs immediately after removal of orthodontic brackets, whereby zones of non-cavitated demineralization developed (even as early as one month into bracket placement) about the previously bonded bracket $[19,23]$; however, these zones are usually able to remineralize to some extent over a month or two using standard oral hygiene practices combined with the natural remineralizing potency of saliva [23-25]. However, topical remineralization therapies may be used to accelerate the recovery $[19,26]$.

Because bracket placement on the facial/labial surfaces allow for facile monitoring, there seems to be an 'understandable' patience involved in the remineralization of the demineralized tooth structure. In contrast, occlusal and interproximal regions of posterior teeth can be more challenging to monitor. Perhaps this plays a role in a seemingly greater 'need' to address evidence of demineralization, even non-cavitated lesions, with more invasive procedures, such as restorations. While the desire to immediately address the patient's tooth may be done in good faith and as a means of thwarting further decay, the clock on the lifetime of the restoration is immediately begun, signaling the onset of a recurring and costly problem over the patient's lifetime $[1,21]$. Sometimes referred to as the 'death spiral' of restorations, the gradual failure of restorations is familiar to dental practitioners and each restored tooth is expected to be addressed again throughout the patient's life: between $50 \%$ and $75 \%$ of posterior amalgam restorations fail within 10 years; even worse, composite (i.e non-amalgam) restorations manifest reduced longevity, along with restorations made in primary dentition [21]. The relevance to a child then is clear, and contributes to the prevalence of U.S. children with restorations by the age of 17 : children bearing restorations within the first part of their lifetime will mature into adulthood bearing increased risk for costly and more invasive procedures in a bid to save the tooth.

Thus, avoidance of the 'death spiral' restorative cycle and preservation of existing tooth structure for as long as possible are of paramount importance. In a recent meta-analysis study evaluating over 18,000 practitioners, Innes and Schwendicke found that over $21 \%$ would opt for the invasive 'drill and fill' option for enamel-only lesions compared to less-invasive approaches [27]. Separately, Gordan et al reported in 2012 that among 197 small (58\%, or 114), large (37\%, or 72$)$ and public health $(6 \%$, or 11$)$ dental practices in the Dental Practice-based Research Network (in the United States, Denmark, Norway and Sweden), 75\% (or, 7,073) restorations were replaced compared to the $25 \%$ (or, 2,411) that were repaired [28]. Among all three dental practice types, secondary caries was the major reason (i.e. $43 \%$ ) for justifying replacement or repair [28]. Notably, larger and/or public health practices were more likely to repair than replace restorations compared to small group practices. But among all three practice types, younger graduates from dental schools and those having been the original dentist who made the restoration conferred a significantly greater tendency to make repairs compared to replacements [28].

Indeed, with the benefit of decades of experience and development of innovative approaches and therapies, understanding how to manage carious lesions while preserving tooth structure continues to evolve, as evidenced with the 2016 publication by the ICCC on managing carious lesions. In particular the ICCC pointed out that even dentine carious lesions in the primary dentition might be manageable - along with responsible periodic assessments - using non-restorative methods, including sealants and resin-infiltration (especially for occlusal surfaces), biofilm removal and remineralization therapies. With respect to permanent dentition, dentist-patient efforts should be made to arrest/inactivate and/or reverse the lesion with the aim of avoiding the dreaded restoration cycle. If such efforts cannot improve the stability and health of the tooth, then restorative intervention is appropriate. And for further details on this topic, the reader is strongly encouraged review the ICCC 2016 publication [1].

Despite the usual challenges, these are exciting times within dentistry, with actionable options available to improve the patient's outcome. With an evolving trend toward noninvasive management of non-cavitated lesions, access and use of effective therapies (fluoride-based, especially), and improved dentist-patient communication (i.e. not just a one-way verbal recommendations), there is a great future ahead for our children! 


\section{References}

1. Schwendicke F, Frencken JE, Bjørndal L, M. Maltz, D.J. Manton, D. Ricketts et al. Managing carious lesions: consensus recommendations on carious tissue removal. Advances in Dental Research. 2016;28(2):58-67.

2. Murdoch-Kinch CA, McLean ME. Minimally invasive dentistry. Journal of the American Dental Association. 2003; 134(1):87-95. doi org/10.14219/jada.archive.2003.0021

3. Dye BA, Tan S, Smith V, Lewis BG, Barker LK, Thornton-Evans G, et al. Trends in oral health status: United States, 1988-1994 and 199204. National Center for Health Statistics. Vital Health Statistics. 2007;11(248):1-92.

4. Miller WD. Influence of Civilization on Decay. In: Micro-Organisms of the Human Mouth Philadelphia: S.S. White Dental Mfg. Co. 1890.

5. American Academy of Pediatric Dentistry, Clinical Affairs Committee. Guideline on Periodicity of Examination, Preventive Dental Services, Anticipatory Guidance/Counseling, and Oral Treatment for Infants, Children, and Adolescents. 2013;37(6):123-130.

6. Karlinsey RL. Fluoride varnishes: why they work and what to look for. EC Dental Science. 2016;5(6):1220-1223.

7. Petersson LG, Twetman S, Pakhomov GN. Fluoride varnish for community-based caries prevention in children. Geneva: World Health Organization; 1997. Report No.: WHO/NCD/ORH/FV/97.1.

8. Centers for Disease Control and Prevention. Recommendations for Using Fluoride to Prevent and Control Dental Caries in the United States. MMWR. 2001;50(RR14):1-42.

9. American Academy of Pediatric Dentistry, Liaison with other Groups Committee. Policy on Use of Fluoride. 2008; 37(6): 43-44.

10. Lense E, Koskela L. Georgia Oral Health Prevention Program Fluoride Varnish Manual 2007. Georgia Department of Human Resources, Division of Public Health; January 2008. Publication No. DPH08.168HW.

11. New York State Department of Health. [cited February 16, 2017].

12. Weyant RJ, Tracy SL, Anselmo T, Beltrán-Aguilar ED, Donly KJ, Frese WA et al. Topical fluoride for caries prevention: Executive summary of the updated clinical recommendations and supporting systematic review. Journal of the American Dental Association. 2013;144(11):1279-1291.

13. Moyer VA. Prevention of Dental Caries in Children from Birth Through Age 5 Years: US Preventive Services Task Force Recommendation Statement. Pediatrics. 2014;133(6):1-10.

14. Dean H, McKay FS. Production of mottled enamel halted by a change in common water supply. American Journal of Public Health 1939;29(6):590-596.Karlinsey RL. Fluoride and the water supply. EC Dental Science. 2017;7(2):64-65
15. Stookey GK. Critical evaluation of the composition and use of topical fluorides. Journal of Dental Research. 1990; 69(Spec Iss):820-823. doi: $10.1177 / 00220345900690 S 154$

16. Tavss EA, Mellberg JR, Joziak M, Gambogi RJ, Fisher SW. Relationship between dentifrice fluoride concentration and clinical caries reduction. American Journal of Dentistry. 2003;16(6):369-374.

17. Stookey GK, Mau MS, Isaacs RL, Gonzalez-Gierbolini C, Bartizek $\mathrm{RD}$, Biesbrock AR. The relative anticaries effectiveness of three fluoride-containing dentifrices in Puerto Rico. Caries Research. 2004;38(6):542-550. DOI: 10.1159/000080584

18. O’Reilly MM, John Featherstone. Demineralization and remineralization around orthodontic appliances: an in vivo study. American Journal of Orthodontics and DentofacialOrthopedics. 1987;92(1):33-40.

19. Misra S, Daly B, Dunne S, Millar B, Packer M, Asimakopoulou K. Dentistpatient communication: what do patients and dentists remember following a consultation? Implications for dental compliance. Patient Preference and Adherence. 2013;7:543-549. doi: 10.2147/PPA. S43255

20. Sheiham, A. Minimal intervention in dental care. Medical Principles and Practice. 2002;11(suppl1):2-6.

21. Thaper R, Karlinsey RL. Clinical observations on the remineralization of Stage 1 enamel caries lesions using a tray-based protocol: a case report. Int Dent Oral Health. 2015;2(1):1-4. doi.org/10.16966/23787090.151

22.Willmot DR. White lesions after orthodontic treatment: does low fluoride make a difference? Journal of Orthodontics. 2004;31(3):235242.

23. Head J.A study of saliva and its action on tooth enamel in reference to its hardening and softening. Journal of the American Medical Association. 1912;59(24):2118-2122. doi:10.1001/jama.1912.04270120103005

24. Pickel FD, Cort W, Starr N, Bilotti A, Pigman W. Evaluation of enamel-rehardening agents in saliva. Journal of Dental Research. 1965;44(5):855-859.

25. Du M, Cheng N, Tai B, Jiang H, Li J, Bian Z. Randomized controlled trial on fluoride varnish application for treatment of white spot lesion after fixed orthodontic treatment. Clinical Oral Investigations. 2012;16(2):463-468. doi: 10.1007/s00784-011-0520-4

26. Innes NPT, Schwendicke F. Restorative thresholds for carious lesions systematic review and meta-analysis. Journal of Dental Research. 2017;1-8. doi: 10.1177/0022034517693605

27. Gordan VV, Riley III JL, Geraldeli S, Rindal DB, Qvist V, Fellows JL et al. Repair or replacement of defective restorations by dentists in the Dental PBRN. Journal of the American Dental Association. 2012;143(6):593-601. 